\title{
TITLE:
}

\section{Annotations by Takushi Horita on Tokioka's paper}

AUTHOR(S):

Miyazaki, Katsumi

CITATION:

Miyazaki, Katsumi. Annotations by Takushi Horita on Tokioka's paper.

Publications of the Seto Marine Biological Laboratory 2014, 42: 105-107

ISSUE DATE:

2014-04-10

URL:

http://hdl.handle.net/2433/185695

RIGHT: 
Publ. Seto Mar. Biol. Lab., 42: 105-107, 2014

\title{
Annotations by Takushi Horita on Tokioka's paper
}

\author{
KATSUMI MIYAZAKI \\ Seto Marine Biological Laboratory, Field Science Education and Research Center, Kyoto University, \\ Shirahama, Wakayama 649-2211, JAPAN \\ E-mail: miyazaki.katsumi.7e@kyoto-u.ac.jp
}

\section{Introductory Note}

During the preparation for the special presentation, "the 100th anniversary of the birth of the late Professor Takasi Tokioka" held at the Shirahama Aquarium, Kyoto University from 1 June 2013, Drs. Katsumi Miyazaki, Sigeyuki Yamato, and Tetsuya Kato of the Seto Marine Biological Laboratory (SMBL) happened to find a set of printed manuscript entitled "A speculation on the classification system of the Ctenophora" by Tokioka along with an additional handwritten sheet from a mass of his left articles kindly lent by his bereaved family, Ms. Mie Tokioka and Mr. Takashi Tokioka. Later, the newer version of manuscript was discovered from the personal computer in the library of the SMBL by the librarian, Mrs. Michiko Okita. The editorial board of the Publications of the Seto Marine Biological Laboratory acknowledged a high academic value of the manuscripts, and decided to publish the newer version in the present issue of the Publications without modifications excepting some text style followed by the format of the journal (Tokioka, 2014). In addition, the board requested Associate Professor Takushi Horita at Tokai University to write an annotation in Japanese on the Tokioka's manuscripts. The synopsis of the annotation in English made by Miyazaki is shown below with the permission of Horita.

\section{Annotations by Takushi Horita}

The discovered manuscripts consist of about 5,400 words (newer version) with eight sections, and are basically the translation of the chapter "Ctenophora" in the "Systematic Zoology, Supplement (Nakayama Shoten)" written in Japanese (Tokioka, 2000). They have, however, many additional contents and sections not described in the Japanese chapter (Table 1). I show the comparison of contents of the present English manuscript (Tokioka, 2014) to those of the Japanese chapter (Tokioka, 2000) for reference.

\section{Introduction}

The contents of this section almost correspond with the "Traditional classifications" and a part of the "Reexamination of the gastric canal system" of the Japanese chapter.

\section{Important modification in the gastric canal system}

This section corresponds with the main part of the Japanese "Reexamination of the gastric canal system" with more examples.

\section{Feeding habit}

This section corresponds with that under the same title in the Japanese chapter. English version is, however, more detailed. 


\section{KATSUMI MIYAZAKI}

\section{Evolutionary modification flow and classification of the ctenophores}

This is the main part of the manuscript. More information and examples are added to the corresponding section of the Japanese chapter, "An attempt for the new classification system". In this section, Tokioka discussed the evolutionary trends within the order Lampeida and with its related orders, Platyctenida, Beroida and Lobata based on their life style (sedentary or pelagic), morphology and feeding habit. The taxonomical position of the order Ganeshida, Cestida, Thalassocalycida and the family Lobatolampeidae is also discussed by comparing the four characteristics of Lobata, (1) formation of the oral lobes, (2) existence of the auricle, (3) winding and looping of the extensions of the meridional canals, and (4) joining site between the adradial and meridional canals, inclusive of missing of the perradial canals. In conclusion, Tokioka deduced the evolutionary trend as follows: Lampeida -> Prelobata -> Protolobata -> Lobata.

\section{Some considerations on the occurrence of rare species}

This section is presented only in the English manuscript. Tokioka discussed the following themes based on the basic morphology of the order Cydippida: (1) design of the gastric canal system and the distribution of energy to each part of the system, (2) increase of body size and its concerning feeding habit and energy distribution, (3) relationship between the overgrowth and the dissogony and sterility. Tokioka deduced the following route correlating the occurrence of rare species: increase of body size $\rightarrow$ undernutrition $\rightarrow$ immaturity of gonad $->$ cannibalism $->$ suiside of the species.

\section{Handwritten part}

In the handwritten sheet discovered together with the older printed version, Tokioka pointed out the three unresolved taxonomical and biological problems on ctenophorans, (1) taxonomic position of some independent groups such as the Cestida, Thalassocalycida, Ganeshida, and Lobatolampea, (2) biological explanation on the dissogony, and (3) biological explanation on the appearance of swarms of sterile adults. The English manuscript treated with these problems, but (1) and (2) were not in the Japanese chapter.

Considering the contents of the handwritten part (cited below), the discovery of Lobatolampea (Horita, 2000) should inspire Tokioka to revise the Japanese chapter (Tokioka, 2000) with more data and further discussion, which meant that Tokioka really understood the importance of Lobatolampea for ctenophoran taxonomy. Furthermore, the discovered manuscripts prove that Tokioka continued to challenge the taxonomical and phylogenetic problems on ctenophorans to the end of his life. I would like to express my sincere respect to Professor Tokioka to his consistent attitude as a genuine scientist.

\section{Citation of the handwritten part}

There are three problems not yet explained clearly in the taxonomy and the biology of the Ctenophora.

(1) Exact situation is unsettled as to some independent group such as the Cestida, in the classification.

(2) - (3) Biological explanation is not yet given as to the phenomena of the dissogony and the appearances of large swarms of sterile adult forms of some lobateans.

The discovery of Lobatolampea by Horita seems to play a role of the trigger in clarify this series of question. Lobatolampea can be placed easily without any doubt between Lampeida and Lobata. And the close relationship between Lobatolampea and the cestids seems to show the phylogenetical situation of the cestids clearly. The complicated features of the gastric canal system may be simplified by treating the features in relation to the migration of the joining site between the meridional and adradial canal. Then the groups of the ctenophores can be arranged rather easily without any strong abjection as shown in the diagramme. With such consideration, re-examination of the gastric canal system seems to lead us to the understanding of the dissogony and the occurrence of the swarms of sterile adult forms of some lobateans. Thus, the publication of Lobatolampea is urged to permit the successive considerations. 


\section{ANNOTATIONS ON TOKIOKA'S PAPER}

\section{Literature cited}

Horita, T. 2000. An undescribed lobate Ctenophore, Lobatolampea tetragona gen. nov. \& spec. nov., representing a new family, from Japan. Zoologische Mededelingen, 73, 457-464.

Tokioka, T. 2000. Ctenophora. In, Yamada, M. (ed.) Systematic Zoology, Supplement, Nakayama Shoten, Tokyo, pp. 80-84. [in Japanese]

Tokioka, T. 2014. A speculation on the classification system of the Ctenophora. Publications of the Seto Marine Biological Laboratory, 42, 96-104. 